\title{
Design and Experimental Research on Seedling Pick-Up Mechanism of Planetary Gear Train with Combined Non-circular Gear Transmission
}

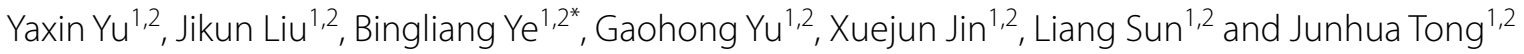

\begin{abstract}
Currently, transplanting mechanisms for dryland plug seedlings in China are mainly semiautomatic and have low efficiency. The rotary seedling pick-up mechanism with a planetary gear train for non-uniform intermittent transmission, and a concave and convex locking arc device, has a large rigid impact. To solve these problems, according to the design requirements for a dryland plug seedling transplanting mechanism, a rotary seedling pick-up mechanism of a planetary gear train with combined non-circular gear transmission of incomplete eccentric circular and noncircular gears was proposed. This has the characteristics of two-times greater fluctuation of the transmission ratio in a cycle, and can achieve a non-uniform continuous drive. Through analysis of the working principle of the seedling pick-up mechanism, its kinematics model was established. The human-computer interaction optimization method and self-developed computer-aided analysis and optimization software were used to obtain a set of parameters that satisfy the operation requirements of the seedling pick-up mechanism. According to the optimized parameters, the structure of the seedling pick-up mechanism was designed, a virtual prototype of the mechanism was created, and a physical prototype was manufactured. A virtual motion simulation of the mechanism was performed, high-speed photographic kinematics tests were conducted, and the kinematic properties of the physical prototype were investigated, whereby the correctness of the theoretical model and the optimized design of the mechanism were verified. Further, laboratory seedling pick-up tests were conducted. The success ratio of seedling pick-up was $93.8 \%$ when the seedling pick-up efficiency of the mechanism was 60 plants per minute per row, indicating that the mechanism has a high efficiency and success ratio for seedling pick-up and can be applied to a dryland plug seedling transplanter.
\end{abstract}

Keywords: Dryland plug seedling transplanter, Rotary seedling pick-up mechanism, Transmission ratio, Non-uniform continuous transmission, Combined non-circular gear transmission, Optimization design

\section{Introduction}

The dryland plug seedling transplanter is a type of agricultural machinery for transplanting crops such as cultivated vegetables and rape plug seedlings into fields. Semiautomatic and automatic transplanting machines have been employed for dryland plug seedling transplanting in China and other countries. Semiautomatic

\footnotetext{
*Correspondence: zist_ybl@zstu.edu.cn

${ }^{1}$ College of Machinery and Automation, Zhejiang Sci-Tech University, Hangzhou 310018, China

Full list of author information is available at the end of the article
}

transplanters plant seedlings via the planting mechanism, and seedling separation and pick-up are completed by hand ("hand-fed"), presenting the problems of consider able labor, seedling leakage, and a low transplanting efficiency. Automatic transplanters can automatically complete the whole process of transplanting plug seedlings via mechanical operations with lower labor costs, high transplanting quality, and high efficiency; thus, they have become a development trend [1-5]. The core working part that determines the quality and efficiency of the dryland plug seedling transplanter is the transplanting mechanism. The automatic transplanting mechanism 
being studied in China and other countries generally consists of two mechanisms: seedling planting and seedling pick-up. The seedling-planting mechanism has been significantly developed and is mature, whereas the automatic seedling pick-up mechanism is the bottleneck restricting the development of the automatic transplanter and has become a popular and challenging research topic throughout the world.

The Japanese researchers Naokatsu et al. [6] developed a gear-link combined seedling pick-up mechanism consisting of a planetary gear train and a crank-slide mechanism that has a low seedling pick-up efficiency of approximately 50 plants per minute per row, a complex structure, and a slideway that is prone to wear. Korean Choi et al. [7] designed a vegetable plug seedling pickup mechanism of the crank-guide rod-slideway type composed of five rods, seedling pick-up claws, and their respective drives. It has a relatively simple structure, but the seedling pick-up efficiency is low (only 30 plants per minute), the slideway is prone to wear, and significant vibration occurs during operation. The American researcher Shaw [8] designed an ejection-type seedling pick-up mechanism that could remove seedlings from tray cells through cell drain holes at the bottom of the tray cells via pneumatic ejectors. It has high transplanting efficiency and is suitable for transplanting seedlings to large fields in Europe and the United States. However, the machine has a complex structure and expensive. Thus, it is difficult to fully apply in China $[9,10]$. In China, it is not long to study on automatic dryland seedling pickup mechanism that has been rarely applied. Xu et al. [11] proposed a planar four-bar mechanism for seedling pick-up. The trajectory with sharp tips on its two ends is effective for seedling pick up, but the efficiency of the mechanism is low, and the location of the falling seedlings is not ideal. Zhang et al. [12] designed an automatic transplanting manipulator with three cylinders to control seedling pick-up and delivery using a programmable logic controller. This is suitable for transplanting plug seedlings between trays on two conveyer belts, but not suitable for mechanical transplanting operations in fields. Hui [13] developed an automatic seedling pick-up mechanism with a crank and double sliders that was suitable for tobacco plug seedlings. However, the slideway is prone to wear, and the machine has significant vibrations and creates shock. Cui et al. [14] designed a combinedtype seedling pick-up mechanism with a gear and five bars consisting of a gear box, a crank, a link, a seedling pick-up arm, and seedling pick-up claws. Because the inertial force of the linkage mechanism cannot be completely balanced, the seedling pick-up efficiency is low.

In recent years, Refs. [15-25] of the Agricultural Machinery Institute of Zhejiang Sci-Tech University in
China have proposed three types of automatic rotary seedling pick-up mechanisms composed of a planetary gear train and seedling pick-up arms, which work stably and efficiently. The aim of this work was to solve the problems of seedling pick-up mechanisms, such as the complex structures, high costs, low efficiency of seedling pick-up, large vibration during operation, and unsuitability for transplanting plug seedlings in China. In this system, two seedling pick-up arms are arranged symmetrically on the rotary box, and two seedlings are extracted in a working cycle. Yu et al. proposed a rotary seedling pick-up mechanism with an elliptical gear, incomplete cylindrical gear transmission, and a concave and convex locking device. To simplify the mechanism, Yu et al. proposed a rotary seedling pick-up mechanism with an elliptical gear and incomplete non-circular gear transmission, as well as a concave and convex locking arc device. These two seedling pick-up mechanisms can achieve the requirements of non-uniform intermittent transmission and trajectory of seedling pick-up, but a rigid impact occurs when the convex and concave locking arcs of the mechanism enter and disengage meshing, which affects the success ratio and speed of seedling pick-up. Zhao et al. proposed a rotary seedling pick-up mechanism with non-uniform continuous transmission of the planetary gear train using two-order general non-circular gears. However, the transmission ratio of the planetary gear train with the two-order general non-circular gears in the seedling pick-up mechanism can achieve only a two-times small fluctuation in a period, and the ratio of the two peaks is only 1.8 . Neither the depth of seedling pick-up nor the posture of seedling pushing are ideal, it is necessary to design a larger-force arm, and the dynamics performance is insufficient. In this paper, a new type of rotary plug seedling pick-up mechanism is proposed. It consists of a planetary gear train with combined noncircular gear transmission of incomplete eccentric circular and non-circular gears that can achieve non-uniform continuous transmission with kinematic characteristics of two-times greater fluctuation of the transmission ratio in a cycle. Studies on the seedling pick-up mechanism were performed, including kinematics modeling and analysis, structure design, virtual motion simulation, prototype tests, and seedling pick-up tests.

\section{Design Requirements of Rotary Seedling Pick-Up Mechanism}

For automatically transplanting dryland plug seedlings, the automatic transplanting operation scheme shown in Figure 1 was adopted, in which the rotary seedling pickup mechanism (Figure 1(a)) matches the duckbill-type planting mechanism (Figure 1(b)) developed at our institute to ensure a high success ratio, low seedling-damage 


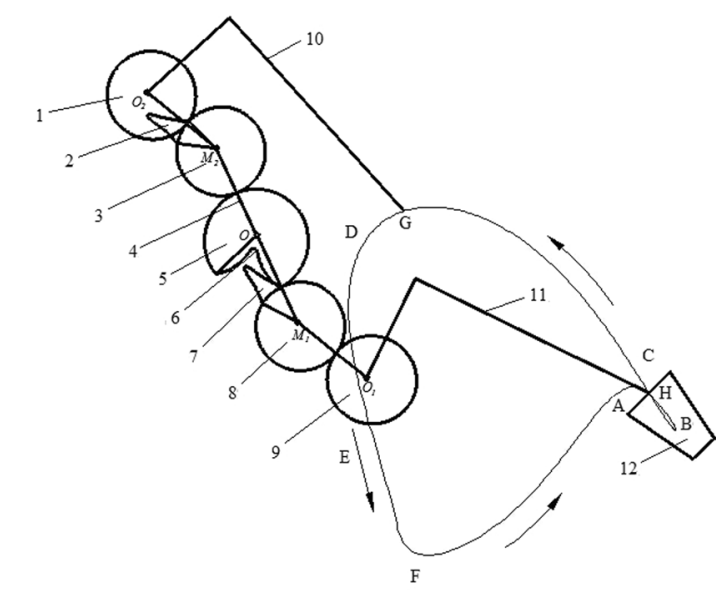

a Seedling pick-up mechanism of the planetary gear train with combined non-circular gear transmission

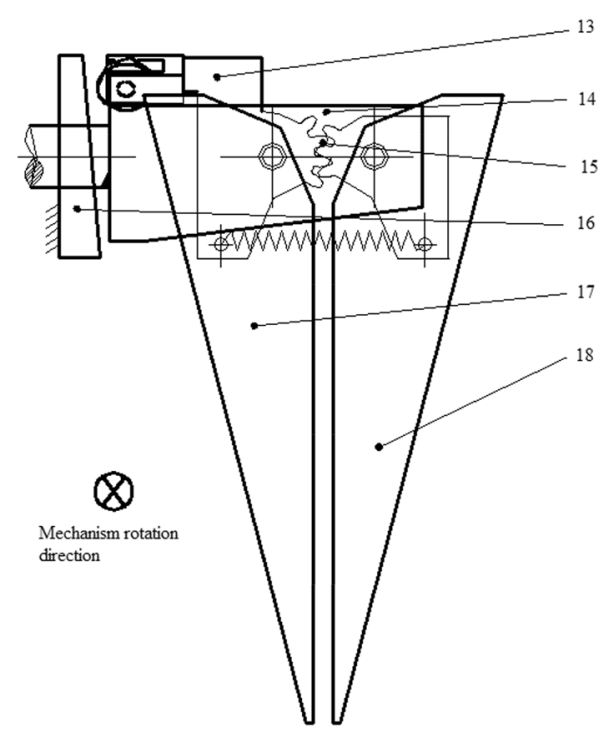

b Duckbill-type planting mechanism

Figure 1 Scheme of the automatic transplanting operation for dryland plug seedlings: 1,9. Planetary non-circular gear; 2,7. Incomplete non-circular gear; 3,8. Non-circular gear; 4. Planetary carrier; 5. Incomplete eccentric circular gear; 6. Incomplete non-circular gear; 10,11. Seedling pick-up arm; 12. Plug seedling tray; 13. Roller rod; 14. Holder; 15. Left and right swing gears; 16 . End cam; 17. Left planting mouth; 18. Right planting mouth; ABCDEFA: Motion trajectory

ratio, and high seedling-standing ratio. In operation, the rotary seedling pick-up mechanism extracts plug seedlings from the seedling tray and places them into the duckbill-type planting mouth after the process of seedling carrying and pushing. Then, the seedlings fall into holes, which are opened by the planting mouth, while compaction wheels cover them with soil.
The rotary plug seedling pick-up mechanism is the core part of the automatic transplanting machine, including the transmission part of the planetary gear mechanism and the executive part of the seedling pick-up arm. Seedling pick-up needles on the seedling pick-up arm comprise the execution end of the mechanism, and the cusp trajectory and posture of the seedling pick-up arm directly affect quality of seedling pick-up and pushing. According to comprehensive analysis of many types of seedling pick-up trajectories and the requirements of the seedling pick-up arm posture, the seedling pick-up trajectory $A B C D E F A$ shown in Figure 1(a), which is the motion trajectory formed by the cusp of the seedling pick-up arm, is proposed.

The trajectory can be divided into four parts corresponding to four working processes: seedling pick-up, seedling transportation, seedling pushing, and return stroke. (1) Trajectory $A B C$ of seedling pick-up. Seedling pick-up needles are inserted into the seedling tray and slowly clamp the plug seedling. When the needles reach point $B$, the seedling is completely clamped. It is then extracted approximately perpendicular to the seedling tray. (2) Trajectory $C D E$ of seedling transportation. The extracted seedling is transported to the seedling pushing position. (3) Trajectory EF of seedling pushing. The seedling pushing rod moves toward the cusp and drives the needles open; then, the seedling falls into the planting mouth of the planting mechanism. (4) Trajectory $F A$ of return stoke. The seedling pick-up mechanism returns to the initial position for the next operation cycle.

The seedling pick-up mechanism completes four successive procedures of seedling pick-up, seedling transportation, seedling pushing, and return stroke in a cycle, and the seedling pick-up trajectory should form a slender ring. To avoid motion interference between the needles and the seedling tray, the inner concave trajectory of the needles should be formed before they enter the tray. During the process of the seedling needles entering and leaving the seedling bowl tray, the needles should move very little. That is, the width of the ring should be as small as possible to prevent damage to the plug seedlings. The needles should leave perpendicular to the tray. When the seedling is pushed, the seedling-pushing angle should be sufficiently large for the seedling to fall into the planting mechanism with good gesture.

\section{Kinematic Analysis of Rotary Seedling Pick-Up Mechanism}

\subsection{Structure and Working Principle of Seedling Pick-Up Mechanism}

According to the design requirements of the rotary seedling pick-up mechanism, a new type of rotary seedling pick-up mechanism involving a planetary gear train with 
combined non-circular gear transmission of incomplete eccentric circular and non-circular gears was proposed, as shown in Figure 1(a). The seedling pick-up mechanism consists of two planetary non-circular gears $(1,9)$, two middle gears (non-circular gear 3 and incomplete non-circular gear 2, non-circular gear 8 and incomplete non-circular gear 7), a planetary carrier (4), a sun gear (incomplete eccentric circular gear 5 and incomplete non-circular gear 6), and two seedling pick-up arms (10, 11). The sun gear and middle gears employ combined non-circular gear transmission with incomplete eccentric circular and non-circular gears; thus, non-uniform motion and continuous transmission can be achieved. After the optimization design of the mechanism is complete, the transmission ratio exhibits two times fluctuation continuously and sharply, and the double-peak ratio is 5.56 [26].

The seedling pick-up mechanism is centro symmetric with the sun gear. The underside structure shown in Figure 1(a) is considered as an example to analyze the working principle of the mechanism. $O$ is the rotation center of the planetary carrier, $M_{1}$ and $M_{2}$ are the rotation centers of the middle gears, and $O_{1}$ and $O_{2}$ are the rotation centers of the planetary gears. The curve $A B C D E F$ is the motion trajectory of the cusp of the seedling pick-up arm.

During the operation of the seedling pick-up mechanism, the sun gear is fixed, and the planetary carrier rotates counterclockwise with a uniform speed around point $O$, driven by the central axis. The alternate meshing of two gear pairs in the combined non-circular gear transmission achieves a non-uniform continuous drive with two-times greater amplitude fluctuation of the transmission ratio in a cycle. The combined middle gear consisting of incomplete non-circular gear 7 and noncircular gear 8 rotates around point $O$, along with the planetary carrier, and also revolves counterclockwise around the rotation center $M_{2}$ on the planetary carrier. Similarly, when the planetary non-circular gear 9 rotates around rotation center $O$ along with the planetary carrier, it rotates clockwise around the rotation center $\mathrm{O}_{2}$. The seedling pick-up arm is fixed on the planetary gear through the planetary gear axle. After the parameters of the mechanism are optimized, the cusp of the seedling pick-up arm forms a motion trajectory, as shown in Figure 2(a), under the effect of two types of motions.

\subsection{Kinematics Model of Seedling Pick-Up Mechanism}

The kinematics model of the seedling pick-up mechanism was established by considering one side of the mechanism as an example [27-31]. The motion diagram of the seedling pick-up mechanism is shown in Figure 2, and the rectangular coordinate system $O x y$ was established.

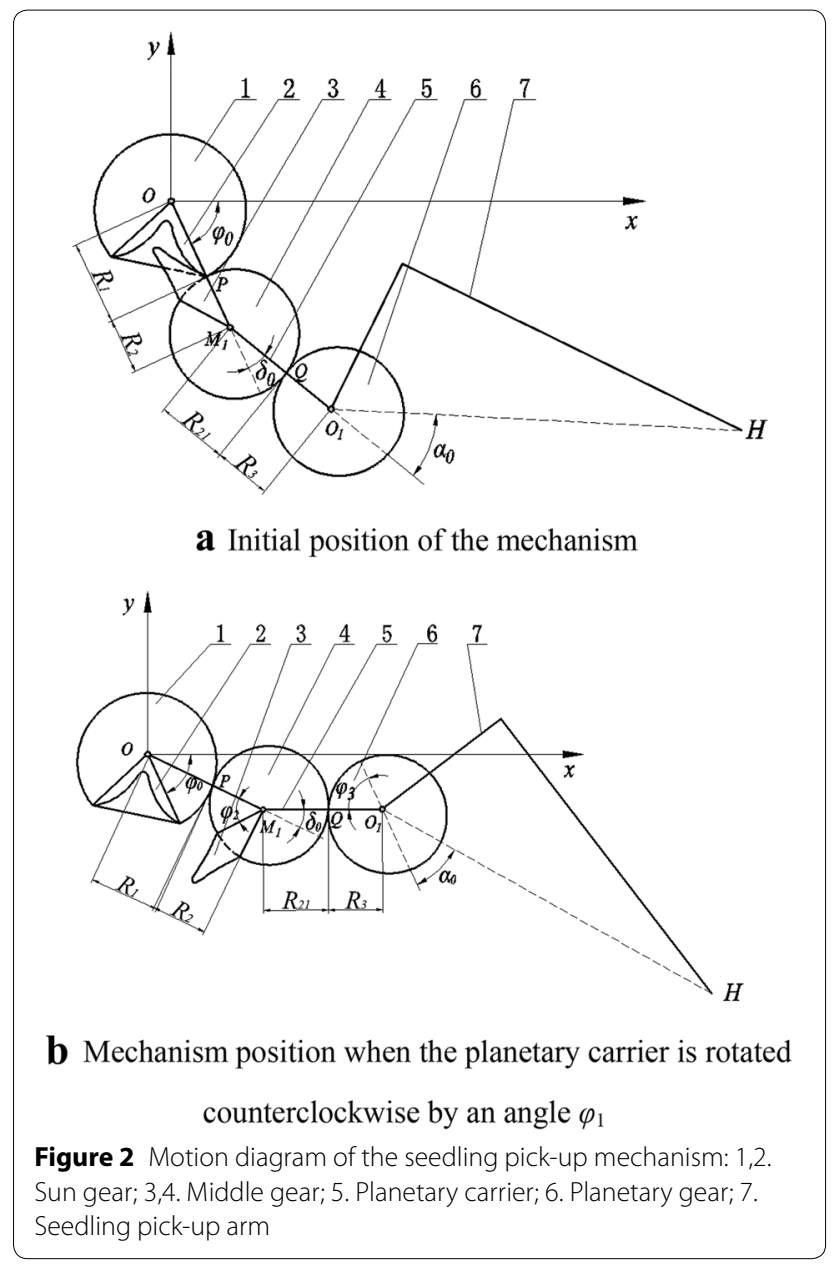

Points $O, M_{1}$, and $O_{1}$ are the rotation centers of the planetary carrier, the middle gear, and the planetary gear, respectively. Point $H$ is the cusp of the seedling pick-up arm. Points $P$ and $Q$ are the meshing points between the middle gear and the sun gear and between the middle gear and the planetary gear, respectively. $\phi_{0}$ is the initial installation angle of the seedling pick-up mechanism, $\delta_{0}$ is the planetary carrier corner (acute angle between lines $M_{1} O$ and $\left.M_{1} O_{1}\right)$, and $\alpha_{0}$ is the installation angle of the seedling pick-up arm. $\beta$ is the central angle of the pitch curve of the toothed part of the incomplete eccentric circular gear. $\alpha$ is the center angle corresponding to the partial pitch curve of the middle non-circular gear meshing with the incomplete eccentric circular gear. $\theta$ is the initial rotation angle of the incomplete eccentric circular gear. $R_{1}$ and $R_{2}$ are the distances from the meshing point $P$ between the sun gear and the middle gear to the rotation centers $O$ and $M_{1}$, respectively. $R_{1}^{\prime}$ and $R_{2}^{\prime}$ are the radius vectors of the meshing pitch curves of the incomplete non-circular gears 2 and 3, respectively. $R_{21}$ and $R_{3}$ are distances from the meshing point $Q$ between the middle 
gear and the planetary gear to rotation centers $M_{1}$ and $O_{1}$, respectively.

\subsubsection{Displacement Model of Seedling Pick-Up Mechanism}

When the planetary carrier rotates counterclockwise by the angle $\varphi_{1}$ from the initial position of the mechanism shown in Figure 2(a), the rotation angles of the middle gear and the planetary gear relative to the planetary carrier are $\varphi_{2}$ and $\varphi_{3}$, respectively, as shown in Figure 2(b).

(1) Angular-displacement analysis of the middle gear relative to the planetary carrier

The drive of the middle gear and the sun gear is a combined non-circular gear transmission. The transmission of the two pairs of gears should satisfy the requirement that the pitch-curve perimeters of the meshing parts are equal during meshing. Then, the analysis and solution of the angular displacement of the middle gear relative to the planetary carrier can be divided to two cases.

When the planetary carrier rotates by the angle $\varphi_{1}$ from - $\varphi_{0}$ to $\beta-\varphi_{0}$, the middle non-circular gear 4 meshes with the incomplete eccentric circular gear 1 . Thus, the following equation is obtained:

$$
\varphi_{2}=\int_{-\varphi_{0}}^{\varphi_{1}} \frac{R_{1}\left(\varphi_{1}\right)}{R_{2}\left(\varphi_{2}\right)} \mathrm{d} \varphi_{1},
$$

where

$$
\begin{aligned}
& R_{1}\left(\varphi_{1}\right)=e \cos \left(\varphi_{1}+\theta\right)+\sqrt{R^{2}-e^{2} \sin ^{2}\left(\varphi_{1}+\theta\right)}, \\
& R_{2}\left(\varphi_{2}\right)=L-R_{1}\left(\varphi_{1}\right) .
\end{aligned}
$$

Here, $R$ and $e$ represent the radius and eccentric distance, respectively, of the incomplete eccentric circle, and $L$ represents the center distance between the middle gear and the sun gear.

Using Eqs. (1) and (3), the following equation is obtained:

$$
\alpha=\int_{-\varphi_{0}}^{\beta-\varphi_{0}} \frac{R_{1}\left(\varphi_{1}\right)}{L-R_{1}\left(\varphi_{1}\right)} \mathrm{d} \varphi_{1}
$$

According to Eq. (4), the center distance $L$ is calculated using numerical integration after the parameters $\beta, \alpha, \boldsymbol{R}$, $\boldsymbol{e}$, and $\theta$ are determined.

To ensure the completeness of the middle non-circular gear and the smoothness and continuity of the periodic pitch curve, the pitch-curve equation for the middle noncircular gear 4 that does not mesh with the sun gear is

$$
R_{2}\left(\varphi_{2}\right)=b_{0}+b_{1} \varphi_{2}+b_{2} \varphi_{2}^{2}+\mathrm{b}_{3} \varphi_{2}^{3}, \quad \alpha \leq \varphi_{2} \leq 2 \pi .
$$

In summary, the pitch-curve equation for the middle non-circular gear is

$$
R_{2}\left(\varphi_{2}\right)=\left\{\begin{array}{lc}
L-R_{1}\left(\varphi_{1}\right), & -\varphi_{0} \leq \varphi_{1} \leq \beta-\varphi_{0} \\
b_{0}+b_{1} \varphi_{2}+b_{2} \varphi_{2}^{2}+b_{3} \varphi_{2}^{3}, & \alpha \leq \varphi_{2} \leq 2 \pi .
\end{array}\right.
$$

In Eq. (6), the coefficients $b_{0}, b_{1}, b_{2}$, and $b_{3}$ are calculated according to the requirements of the smoothness and continuity of the periodic pitch curve of the middle non-circular gear.

When the planetary carrier rotates by the angle $\varphi_{1}$ from $\beta-\varphi_{0}$ to $2 \pi-\varphi_{0}$, the incomplete non-circular gears 2 and 3 mesh with each other, and the following equation is obtained:

$$
\varphi_{2}=\int_{\beta-\varphi_{0}}^{\varphi_{1}} \frac{R_{1}^{\prime}\left(\varphi_{1}\right)}{R_{2}^{\prime}\left(\varphi_{2}\right)} \mathrm{d} \varphi_{1},
$$

where $R_{2}^{\prime}\left(\varphi_{2}\right)=L-R_{1}^{\prime}\left(\varphi_{1}\right)$.

The transmission-ratio function of the incomplete noncircular gears 2 and 3 is

$$
i_{2}\left(\varphi_{1}\right)=\frac{R_{2}^{\prime}\left(\varphi_{2}\right)}{R_{1}^{\prime}\left(\varphi_{1}\right)} .
$$

Here, the transmission-ratio function is constructed as follows:

$$
i_{2}\left(\varphi_{1}\right)=a_{0}+a_{1} \sin \varphi_{1}+a_{2} \cos \varphi_{1} .
$$

In Eq. (9), the transmission-ratio coefficients $a_{1}, a_{2}$ and $a_{3}$ can be determined according to the continuity condition of the transmission ratio of the two pairs of gears.

According to Eqs. (8) and (9), the pitch-curve equation for the transmission of the incomplete non-circular gears 2 and 3 is

$$
\left\{\begin{array}{l}
R_{1}^{\prime}=\frac{L i_{2}\left(\varphi_{1}\right)}{1+i_{2}\left(\varphi_{1}\right)}, \\
R_{2}^{\prime}=\frac{L}{1+i_{2}\left(\varphi_{1}\right)} .
\end{array}\right.
$$

(2) Angular-displacement analysis of the planetary gear relative to the planetary carrier

When the middle gear meshes with the planetary gear, the two gears should satisfy the requirement that the pitch-curve perimeters of their meshing parts are equal. Then, the following equation is obtained:

$$
\varphi_{3}=\int_{0}^{\varphi_{2}} \frac{R_{21}\left(\varphi_{1}\right)}{R_{3}\left(\varphi_{3}\right)} \mathrm{d} \varphi_{2},
$$

where

$$
R_{21}\left(\varphi_{1}\right)=R_{2}\left(\varphi_{2}+\pi-\delta_{0}\right), \quad R_{3}\left(\varphi_{3}\right)=a-R_{21}\left(\varphi_{1}\right) .
$$


Here, $a$ is the distance between the centers of the middle gear and the planetary gear.

When the planetary carrier rotates by the angle $\varphi_{1}$ from zero to $2 \pi$, the middle gear and the planetary gear correspondingly rotate by the angles $\varphi_{2}$ and $\varphi_{3}$, respectively, from zero to $2 \pi$. Thus, the following equation is obtained:

$$
2 \pi=\int_{0}^{2 \pi} \frac{R_{21}}{a-R_{21}} \mathrm{~d} \varphi_{2} .
$$

$R_{21}\left(\varphi_{1}\right)$ can be approximately calculated using $R_{2}\left(\varphi_{2}\right)$ according to the equations below Eq. (11). The distance $a$ between the centers of the middle gear and the planetary gear can be calculated using the numerical-integration method according to Eq. (12) [23]. After $R_{21}\left(\varphi_{1}\right)$ and $a$ are calculated, $\varphi_{3}$ can be calculated using Eq. (11).

The relative displacement of the cusp $H$ of the seedling pick-up arm is

$$
\left\{\begin{array}{c}
X_{H}=L \cos \left(\varphi_{0}+\varphi_{1}\right)+a \cos \left(\varphi_{0}+\varphi_{1}+\delta_{0}\right) \\
+S \cos \left(\varphi_{0}+\varphi_{1}+\delta_{0}+\alpha_{0}+\varphi_{3}\right) \\
Y_{H}=L \sin \left(\varphi_{0}+\varphi_{1}\right)+a \sin \left(\varphi_{0}+\varphi_{1}+\delta_{0}\right) \\
+S \sin \left(\varphi_{0}+\varphi_{1}+\delta_{0}+\alpha_{0}+\varphi_{3}\right)
\end{array}\right.
$$

where $S$ is the distance from the cusp of the seedling pick-up arm to the rotation center of the planetary gear.

\subsubsection{Velocity Model of Seedling Pick-Up Mechanism}

The planetary carrier rotates counterclockwise with a uniform angular speed $\omega_{1}$. The angular speed of the planetary non-circular gear relative to the planetary carrier is

$$
\omega_{3}=\frac{R_{1}}{R_{2}} \frac{R_{21}}{R_{3}} \omega_{1} .
$$

The relative velocity of the cusp $H$ of the seedling pick-up arm can be obtained by taking the derivative of Eq. (13):

$$
\left\{\begin{array}{l}
v_{H x}=-\omega_{1} L \sin \left(\varphi_{0}+\varphi_{1}\right)-a \omega_{1} \sin \left(\varphi_{0}+\varphi_{1}+\delta_{0}\right) \\
-S\left(\omega_{1}+\omega_{3}\right) \sin \left(\varphi_{0}+\varphi_{1}+\delta_{0}+\alpha_{0}+\varphi_{3}\right) \\
v_{H y}=\omega_{1} L \cos \left(\varphi_{0}+\varphi_{1}\right)+a \omega_{1} \cos \left(\varphi_{0}+\varphi_{1}+\delta_{0}\right) \\
+S\left(\omega_{1}+\omega_{3}\right) \cos \left(\varphi_{0}+\varphi_{1}+\delta_{0}+\alpha_{0}+\varphi_{3}\right) .
\end{array}\right.
$$

The resultant relative velocity of the cusp $H$ of the seedling pick-up arm is

$$
v_{H}=\sqrt{v_{H x}^{2}+v_{H y}^{2}}
$$

\section{Optimization Design of Rotary Seedling Pick-Up Mechanism}

To optimize the parameters of the rotary seedling pick-up mechanism for dryland plug seedlings, which is a fuzzy, nonlinear, strong-coupling, and complex optimization problem, the following steps were taken. An optimization design model of the seedling pick-up mechanism was constructed, computer-aided analysis and optimization software for the mechanism was developed, and parameter optimization of the mechanism was finally realized by using the human-computer interaction optimization method [32].

\subsection{Optimization Objectives and Design Variables of Seedling Pick-Up Mechanism}

According to previous research and consideration of the physical properties of dryland plug seedlings, the posture of the seedling pick-up arm, the motion interference, the motion trajectory, and the structure of the mechanism, the optimization objectives of the seedling pick-up mechanism were determined as follows:

1) There should be no motion interference between the two seedling pick-up arms or between the arms and the plug seedling tray.

2) The seedling pick-up trajectory should form a slender ring. The width of the ring should be less than $5 \mathrm{~mm}$, and the length of the seedling pick-up trajectory in the tray should be approximately $30 \mathrm{~mm}$.

3) The posture of the seedling pick-up arm should be appropriate. The trajectory of the seedling pick-up section should be approximately perpendicular to the plug seedling tray, and the seedling-pushing angle should be greater than $50^{\circ}$.

4) The mechanism should be compact, such that the rotation radius of the gearbox is less than $150 \mathrm{~mm}$.

Through kinematic analysis of the seedling pick-up mechanism, the following design variables were selected: the radius and eccentric distance of the incomplete eccentric circle $R$ and $e$, respectively; the central angle corresponding to the pitch curve of the toothed part of the incomplete eccentric circular gear $\beta$; the central angle corresponding to the pitch curve of the meshing part of the middle non-circular gear with the incomplete eccentric circular gear $\alpha$; the initial rotation angle of the incomplete eccentric circle $\theta$; the initial installation angle of the seedling pick-up mechanism $\varphi_{0}$; the installation angle of the seedling pick-up arm $\alpha_{0}$; the corner angle of the planetary carrier $\delta_{0}$; and the distance between the cusp of the seedling pick-up arm and the rotation center of the planetary gear $S$.

\subsection{Analysis of Parameter-Optimization Results for Seedling Pick-Up Mechanism}

Using the visualization development platform of Visual Basic 6.0, computer-aided analysis and optimization software for the design of the seedling pick-up mechanism 


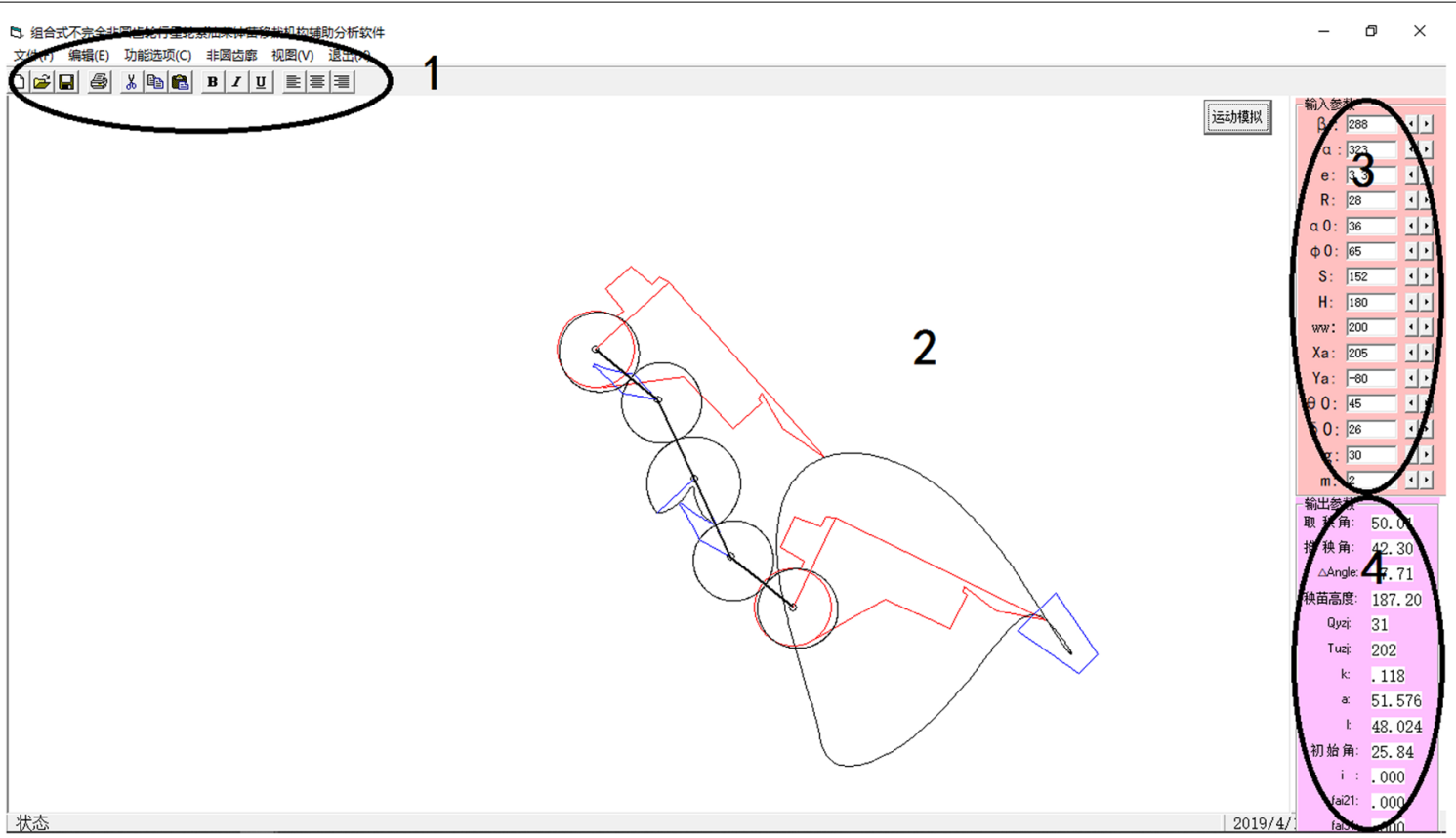

Figure 3 Main interface of the human-computer interaction-aided analysis and optimization software used for the design of the seedling pick-up mechanism: 1. Menu area; 2. Graphic-display area; 3. Parameter-input area; 4. Result-output area

was developed, and its main interface is shown in Figure 3. By using the software to input or adjust the parameters of the mechanism, motion simulation and velocity analysis of the seedling pick-up mechanism were performed, and the motion interference was checked. The influence of the design variables on the mechanism trajectory was analyzed. The tooth profile of the non-circular gear was designed. Real-time outputs of the motion trajectory, the seedling pick-up angle, the seedling-pushing angle, and the difference between these angles were obtained.

According to analysis of the influence of each design parameter on the kinematic trajectory, a set of parameters that satisfy the requirements of seedling pick-up were obtained: $R=28 \mathrm{~mm}, e=3.3 \mathrm{~mm}, \beta=288^{\circ}, \alpha=323^{\circ}$, $\theta=30^{\circ}, \varphi_{0}=65^{\circ}, \alpha_{0}=36^{\circ}, \delta_{0}=26^{\circ}$, and $S=152 \mathrm{~mm}$. The center distance of the gear drive was $L=51.68 \mathrm{~mm}$ and $a=48.12 \mathrm{~mm}$.

After parameter optimization of the mechanism, the motion trajectory of the mechanism was obtained, as shown in Figure 4. The trajectory of the seedling pick-up section forms a slender ring whose width is $1.9 \mathrm{~mm}$. The trajectory of the seedling pick-up section is nearly perpendicular to plug seedling tray, and the trajectory length in the seedling tray is $30.4 \mathrm{~mm}$. The seedling pushing angle is approximately $52^{\circ}$, and the rotation radius of the gearbox is approximately $118 \mathrm{~mm}$. Relative-motion simulation of the seedling pick-up mechanism indicates that

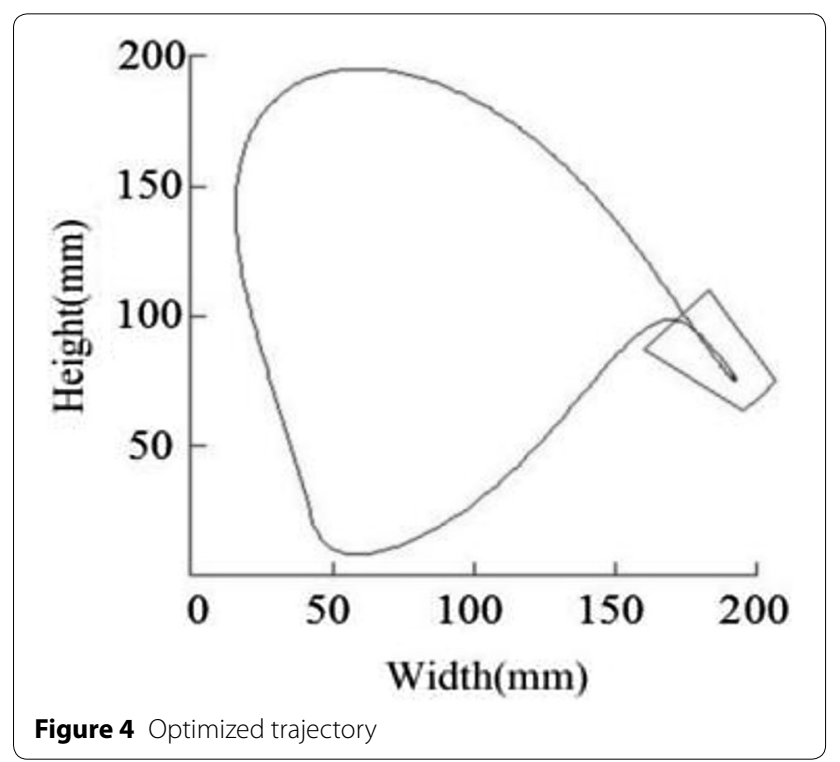

there is no motion interference between the two arms or between the seedling pick-up arm and the seedling tray during the operation of the mechanism. The optimization results satisfy the requirements of the optimization objectives, and the optimized seedling pick-up mechanism satisfies the requirements for transplanting plug seedlings. 


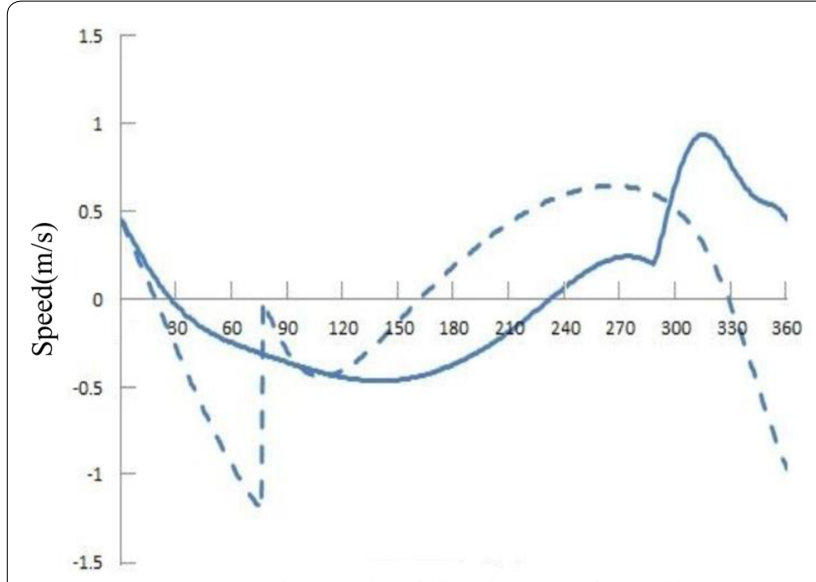

Rotation angle of the planetary frame $\left(^{\circ}\right)$

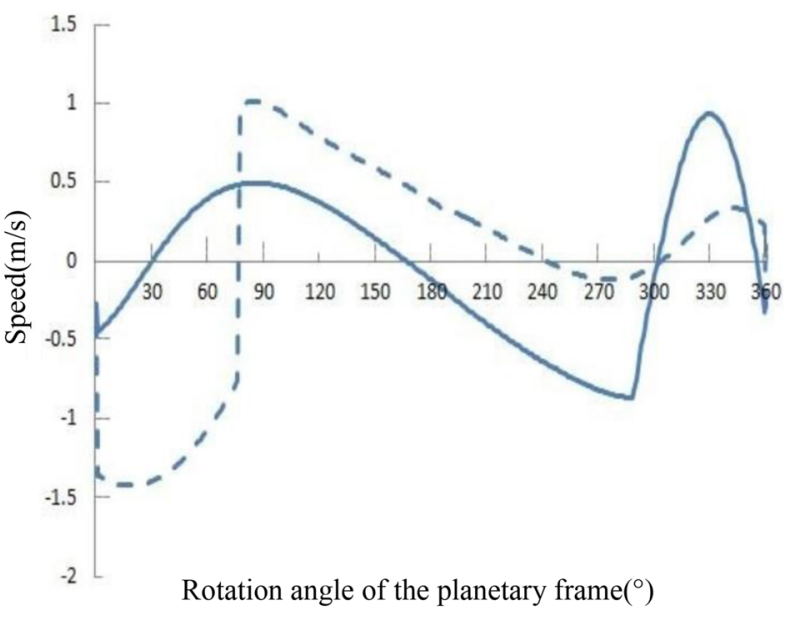

b $Y$-direction velocity curve

a $X$-direction velocity curve

Figure 5 Velocity-curve comparison of the cusp of the seedling pick-up arm for different seedling pick-up mechanisms

As shown in Figure 5, the velocity curve of the cusp of the seedling pick-up arm for the seedling pick-up mechanism designed in this study was compared with that of a previously reported seedling pick-up mechanism with a locking arc device [30]. The dotted and solid lines represent the velocity curves of the previous and proposed seedling pick-up mechanisms, respectively. For the original mechanism, when the rotation angle of the planetary carrier is $0^{\circ}$ and $77^{\circ}$, the $X$ - and $Y$-direction velocities both change suddenly.

When the rotation angle of the planetary carrier is $0^{\circ}$, the concave and convex locking arcs begin meshing, the $X$-direction velocity changes from -0.96 to $0.42 \mathrm{~m} / \mathrm{s}$, and the $Y$-direction velocity changes from -0.38 to $-1.36 \mathrm{~m} / \mathrm{s}$. When the rotation angle of the planetary carrier is $77^{\circ}$, the concave and convex locking arcs finish meshing, the $X$-direction velocity changes from -1.2 to $-0.01 \mathrm{~m} / \mathrm{s}$, and the $Y$-direction velocity changes from -0.76 to $0.98 \mathrm{~m} / \mathrm{s}$. The results indicate that the cusp velocity of the seedling pick-up arm of the original mechanism changes at the moments when the concave and convex locking arc enters and departs meshing, leading to a rigid impact on the original mechanism, which affects the operation stability. For the proposed seedling pick-up mechanism, there are no such changes in the velocity curves, indicating that this mechanism has no impact and runs smoothly, which is beneficial for the transplanting performance.

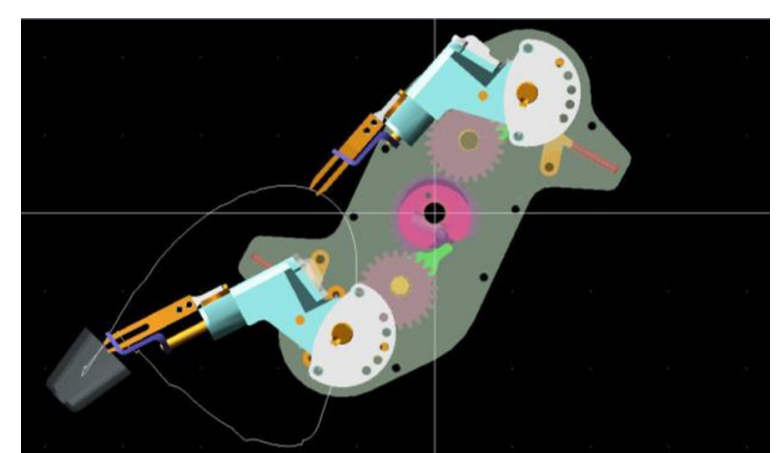

Figure 6 Virtual prototype of the seedling pick-up mechanism

\section{Virtual Simulation and Tests of Rotary Seedling Pick-Up Mechanism}

5.1 Virtual Simulation of Seedling Pick-Up Mechanism

According to the optimized parameters, the structure of the seedling pick-up mechanism was designed. Threedimensional modeling and virtual assembly of the seedling pick-up mechanism were performed using the $U G$ software, and then assembly model was imported into $A D A M S$ to conduct a motion simulation for the mechanism. The motion trajectory and velocity curves of the cusp of the seedling pick-up arm of the mechanism were obtained and compared with theoretical results calculated using optimization analysis software, which verified the correctness of the theoretical model and the design results for the seedling pick-up mechanism. The virtual prototype of the seedling pick-up mechanism is shown in Figure 6. 


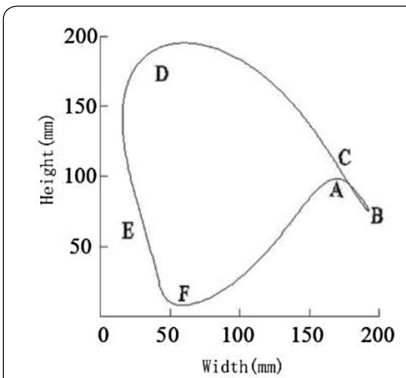

a Theoretical analysis trajectory Figure $\mathbf{7}$ Trajectory comparison for the seedling pick-up mechanism

\subsubsection{Trajectory Analysis of Seedling Pick-Up Mechanism}

The trajectories of the mechanism in the theoretical analysis and the virtual simulation are shown in Figure 7. In the theoretical analysis, the trajectory was obtained through the optimization analysis software. As shown in Figure $7(\mathrm{a})$, the length and width of the ring of the seedling pick-up trajectory were approximately 25 and $1.9 \mathrm{~mm}$, respectively, and the height of the seedling pickup trajectory was approximately $187 \mathrm{~mm}$.

In the virtual simulation, the trajectory was obtained through motion simulation of the virtual prototype. As shown in Figure 7(b), the length and width of the ring of the seedling pick-up trajectory were approximately 25 and $2.3 \mathrm{~mm}$, respectively, and the height of the seedling pick-up trajectory was approximately $167 \mathrm{~mm}$.

Figure 7 indicates that the trajectories of the theoretical analysis and virtual simulation are similar, but there are slight differences in the trajectory height and the returnsection trajectory EFA. For this reason, in the combined non-circular gear transmission, the tooth profiles of the incomplete non-circular gears (sun gear and middle gear) were designed as a similar profiles of cams, and the transmission ratio of the mechanism became smaller. Additionally, the pitch curve had a small surplus after it was arranged with 21 teeth; thus, the remaining pitch curve was arranged in the incomplete non-circular gear in the sun gear, which caused the seedling pick-up mechanism to begin the return procedure earlier than in the previous design. However, these factors do not affect the performance of the seedling pick-up mechanism, because the operation of seedling pushing is completed before the mechanism enters the return procedure, as indicated by the simulation test.

\subsubsection{Velocity Analysis of Seedling Pick-Up Mechanism}

The velocity curves of the theoretical calculation and simulation analysis are shown in Figures 8 and 9, respectively, for a planetary-carrier rotation speed of $60 \mathrm{r} / \mathrm{min}$. Figure $8(\mathrm{a})$ and (b) show the $X$ - and $Y$-direction velocity

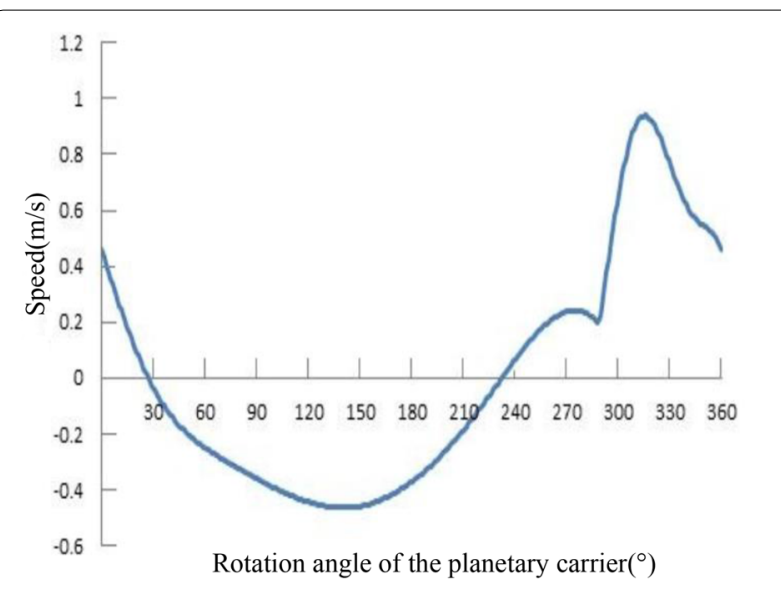

a $X$-direction velocity curve of the theoretical calculation

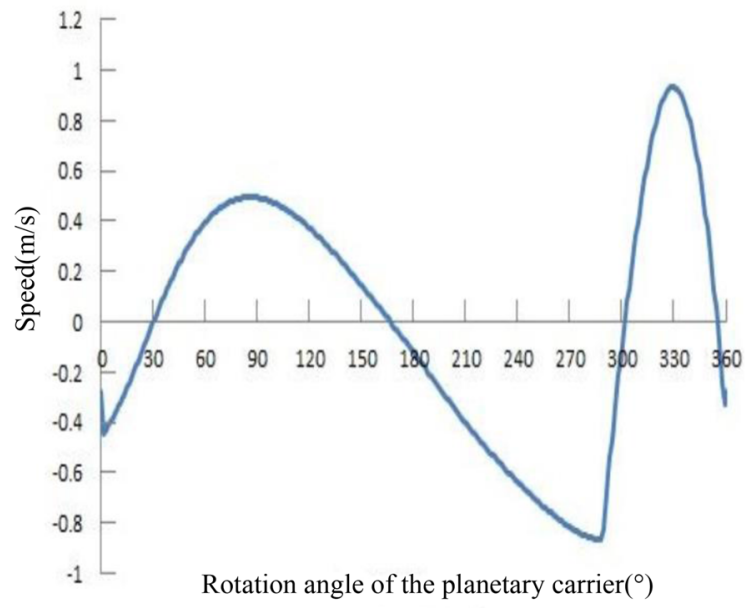

b $Y$-direction velocity curve of the theoretical calculation Figure 8 Theoretical velocity curves

curves for the theoretical calculation, respectively, and Figure 9(a) and (b) show the $X$ - and $Y$-direction velocity curves for the virtual simulation, respectively.

The velocity curves for the simulation analysis and the theoretical calculation are essentially the same. However, a slight difference is observed: when the planetary carrier rotates from $280^{\circ}$ to $360^{\circ}$, there is a wave peak in the $X$ - and $Y$-direction velocity curves, and the peak value in Figure 8(a) and (b) is larger than that in Figure 9(a) and (b). The reason for this is the same as that for the trajectory difference.

\subsection{Kinematics Tests of Seedling Pick-Up Mechanism}

According to the structure design of the seedling pickup mechanism, non-circular gears were processed via wire-cutting and heat-treatment technology. Aluminum alloy parts, including a gearbox, were manufactured in a 


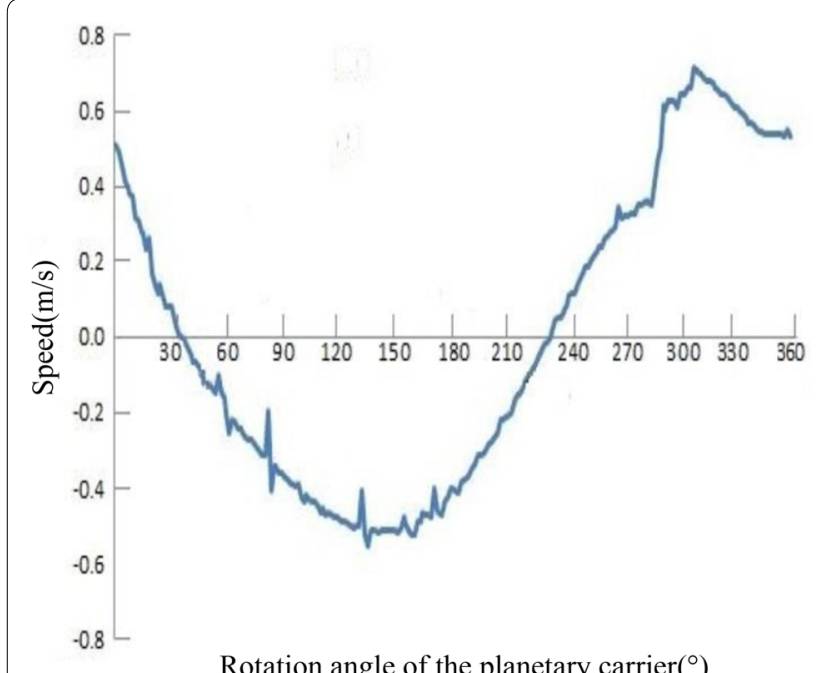

a $X$-direction velocity curve of the simulation analysis

Figure 9 Simulated velocity curves

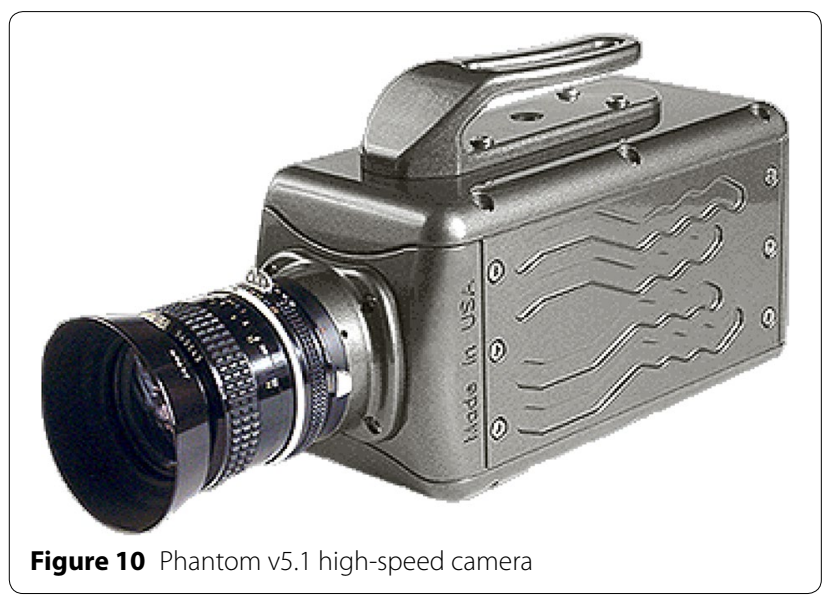

machining center, and then the parts were assembled into a physical prototype of the seedling pick-up mechanism. The mechanism prototype was installed on a self-made test bench to conduct kinematics tests using high-speed photography technology. Figure 10 shows the high-speed camera (Phantom v5.1) used in the kinematics experiments. This camera can obtain high-speed photographs with millions of pixels and is produced by the American VAI Company. It provides high image quality, resolution, and sensitivity. The experimental process was as follows. First, a distinctive marker was placed at the tip of the picking claw. Then, the high-speed camera was installed at a suitable position so that the pick-up mechanism could be displayed on the screen during operation. The
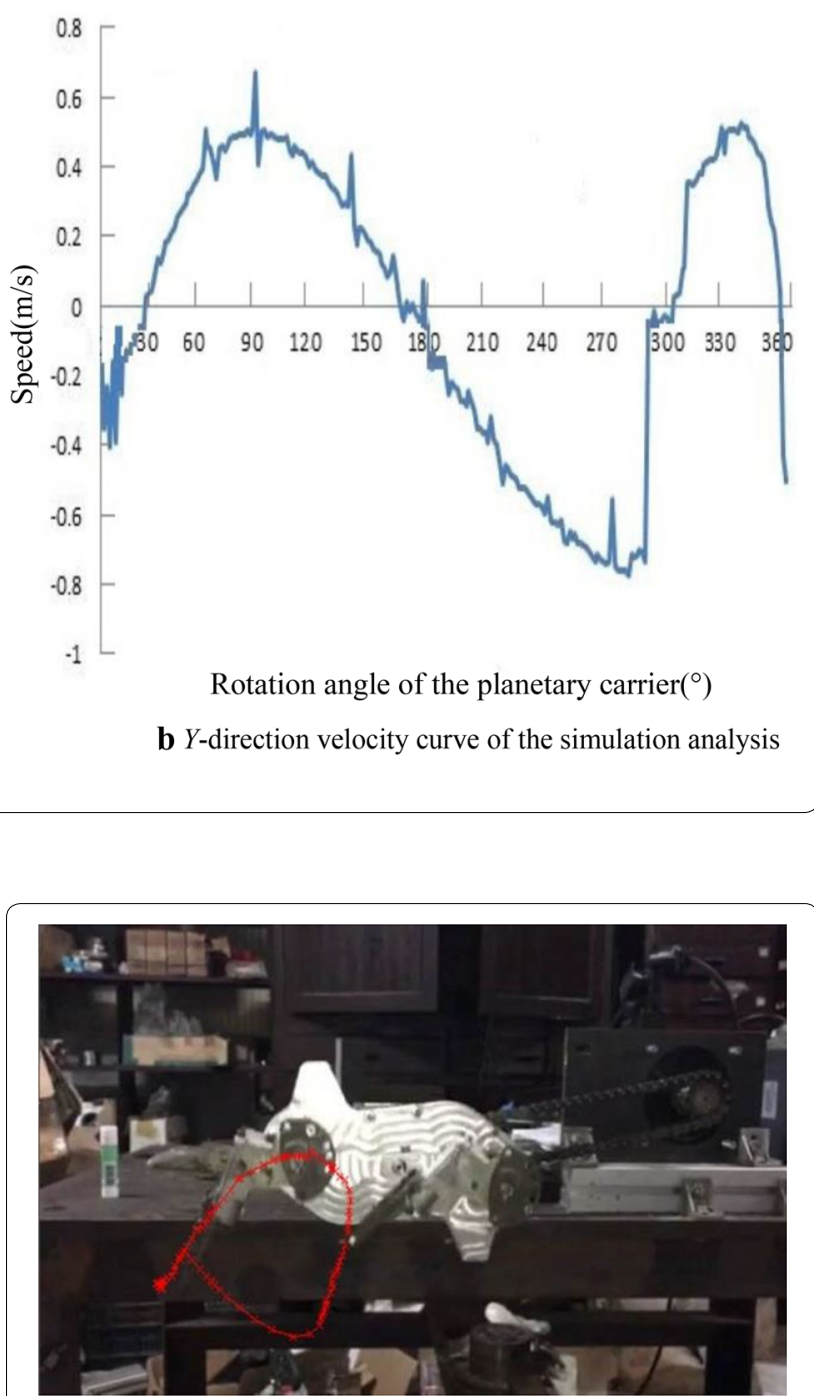

Figure 11 Test and kinematics trajectory of the seedling pick-up mechanism prototype

position and intensity of the light were adjusted to make the marked points clearly visible. The capture rate was set as $370 \mathrm{fps}$. The speed of the drive motor was adjusted to $60 \mathrm{r} / \mathrm{min}$. After the machine operated smoothly, the image acquisition began. Finally, Blaster's MAS image analysis software was used to process and analyze the collected images, and the motion trajectory of the tips of the seedling claws was obtained. The motion trajectory is shown in Figure 11.

Comparing the trajectories of the high-speed photography and virtual simulation shown in Figures 11 and 7(b), respectively, reveals the following differences. For the real trajectory, the angle of seedling pushing at the end of the pushing operation was $47^{\circ}$, which is slightly smaller than 

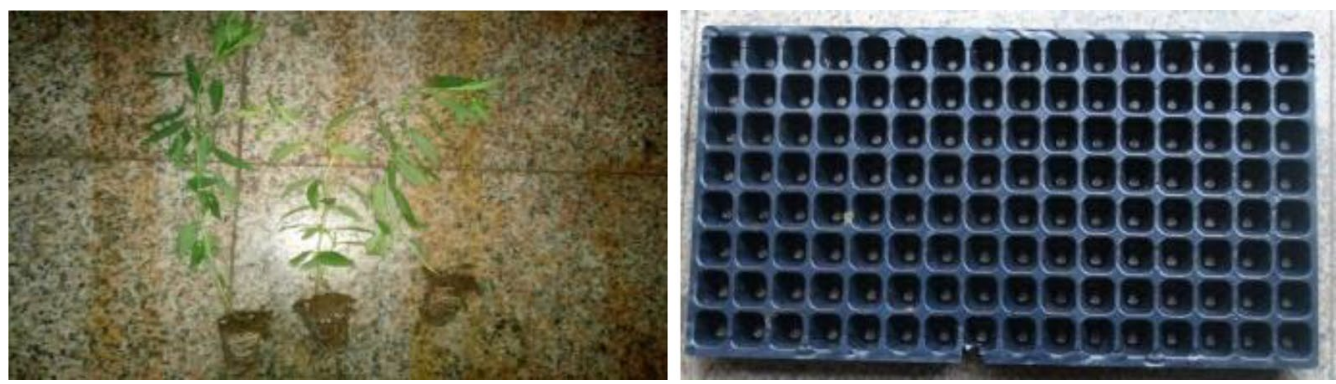

Figure 12 Plug tray and Cordate houttuynia seedlings used for the tests

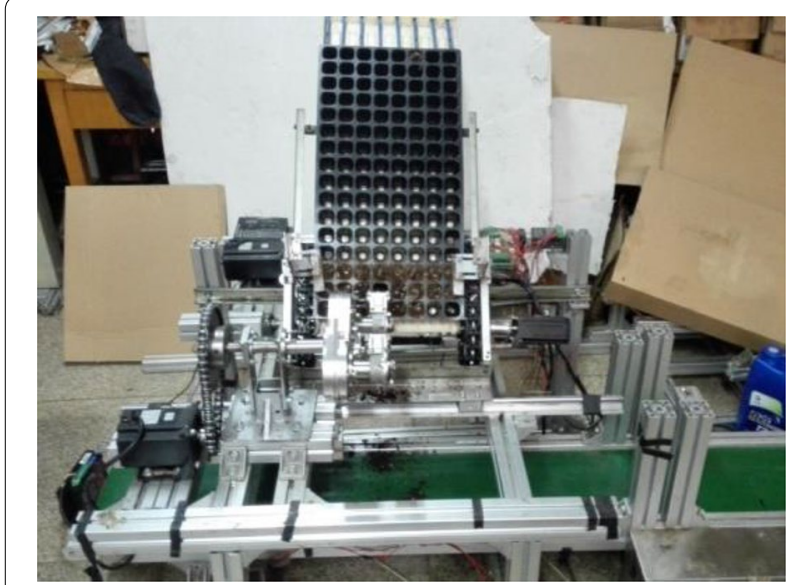

Figure 13 Test bench for the seedling pick-up mechanism

that of the theoretical analysis $\left(50^{\circ}\right)$. The height of the real trajectory was slightly lower than that of the theoretical trajectory.

The main factors affecting the seedling-pushing angle are machining and installation errors and the clearance of the gear profile. In the combined incomplete noncircular gear transmission of this mechanism, a pair of gears employ cam-like transmission. The contours of the incomplete non-circular gears were obtained via a graphical method. For avoiding interference, the actual pitch curve of the incomplete non-circular gears was lower than the theoretical pitch curve, reducing the height of the actual seedling trajectory.

During the operation of the prototype, the seedling pick-up mechanism rotated stably, and there was no motion interference, indicating the effectiveness of the design of the novel seedling pick-up mechanism.

\subsection{Seedling Pick-Up Tests of Proposed Mechanism}

A plug tray with $8 \times 16$ cells and cordate houttuynia seedlings were employed for the tests, as shown in Figure 12 . The mechanism prototype was installed on the self-developed test bench shown in Figure 13, and the rotation speeds of the motor were set as 30,40 , and $50 \mathrm{r} /$ $\mathrm{min}$. In each test, 128 seedlings were extracted. The highspeed camera was used to observe the operation of the seedling pick-up mechanism. The number of seedlings successfully extracted was recorded, and the success ratio was calculated.

The seedling pick-up and pushing moments are shown in Figure 14(a) and (b), respectively, and the seedling pick-up test results are presented in Table 1. The data in the table indicate that when the rotation speed was $30 \mathrm{r} /$ min (seedling pick-up efficiency of 60 plants per minute for a single row), the success ratio of seedling pick-up was $93.8 \%$. Thus, the optimized mechanism can be used in a dryland plug seedling transplanter. As the rotation speed of the mechanism increased, the success ratio of seedling pick-up decreased. The main reasons for seedling pickup failure were the seedlings being too tall and the substrates of the bowl being too dry and loose and thus easily broken.

\section{Conclusions}

(1) According to the mechanical transplanting requirements for dryland seedlings, a new type of rotary seedling pick-up mechanism employing a planetary gear train with combined non-circular gear transmission of incomplete eccentric circular and noncircular gears that can realize non-uniform continuous transmission was proposed. The working principle of the seedling pick-up mechanism was studied, a kinematics analysis of the mechanism was performed, and a kinematics model was established.

(2) The human-computer interaction optimization method was used to obtain the optimal design of the seedling pick-up mechanism. The following set of parameters of the mechanism satisfying the working requirements of mechanical pick-up for dryland seedlings were optimized: the radius 


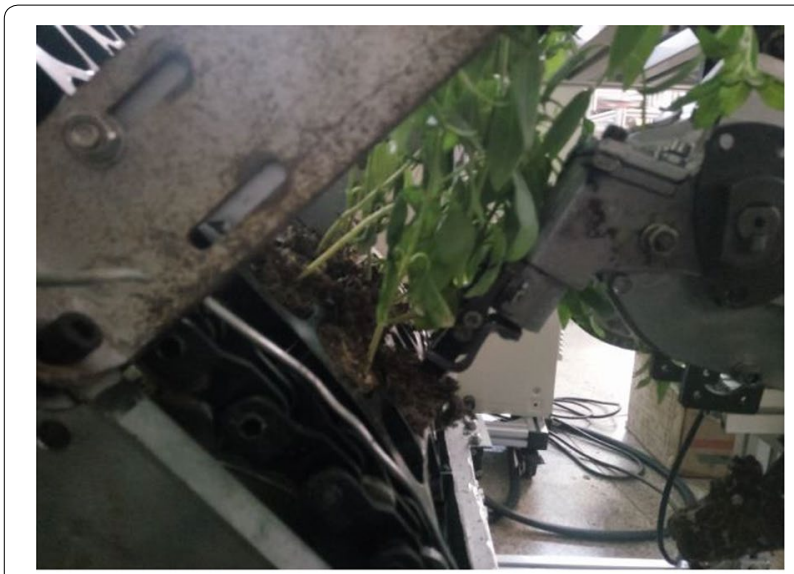

a Seedling pick-up moment

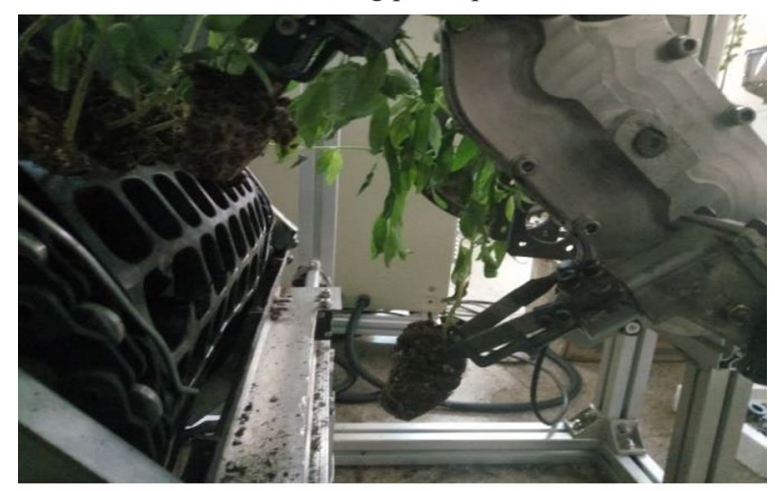

b Seedling-pushing moment

Figure 14 Seedling pick-up tests

Table 1 Results of the seedling pick-up test

\begin{tabular}{llll}
\hline $\begin{array}{l}\text { Rotation } \\
\text { speed }(\mathbf{r} \text { / } \\
\text { min) }\end{array}$ & $\begin{array}{l}\text { Total number } \\
\text { of seedlings } \\
\text { (plant) }\end{array}$ & $\begin{array}{l}\text { Number } \\
\text { of seedlings } \\
\text { successfully } \\
\text { extracted (plant) }\end{array}$ & $\begin{array}{l}\text { Success ratio } \\
\text { of seedling } \\
\text { pick-up (\%) }\end{array}$ \\
\hline 30 & 128 & 120 & 93.8 \\
40 & 128 & 112 & 87.5 \\
50 & 128 & 107 & 83.6 \\
\hline
\end{tabular}

and eccentric distance of the incomplete eccentric circular gear $(R=28 \mathrm{~mm}$ and $e=3.3 \mathrm{~mm}$, respectively), the central angle corresponding to the pitch curve of the toothed part of the incomplete eccentric circular gear $\beta=288^{\circ}$, the central angle corresponding to the pitch curve of the meshing part of the middle non-circular gear with the incomplete eccentric circular gear $\alpha=323^{\circ}$, the initial rotation angle of the incomplete eccentric circular gear $\theta=30^{\circ}$, the initial installation angle of the seedling pick-up mechanism $\varphi_{0}=65^{\circ}$, the installation angle of the seedling pick-up arm $\alpha_{0}=36^{\circ}$, the corner angle of the planetary carrier $\delta_{0}=26^{\circ}$, and the distance between the cusp of the seedling pick-up arm and the rotation center of the planetary gear $S=152 \mathrm{~mm}$. The distance between the centers of the two pairs of gears driving the seedling pick-up mechanism was $L=51.68 \mathrm{~mm}$ and $a=48.12 \mathrm{~mm}$. The kinematics model and optimization design of the seedling pick-up mechanism were verified though a virtual simulation of the mechanism.

(3) High-speed photography kinematics tests and seedling pick-up tests were conducted to study the motion characteristics of the mechanism prototype and to verify its seedling pick-up effect. The success ratio of seedling pick-up was $93.8 \%$ when the seedling pick-up efficiency of the mechanism was 60 plants per minute per row, indicating that the novel mechanism can be applied to dryland plug seedling transplanters.

\section{Authors' Contributions}

BY was in charge of the whole trial; YY and JL wrote the manuscript; GY, XJ, LS and JT assisted with experiments and data analysis. All authors read and approved the final manuscript.

\section{Author Details}

${ }^{1}$ College of Machinery and Automation, Zhejiang Sci-Tech University, Hangzhou 310018, China. ${ }^{2}$ Zhejiang Province Key Laboratory of Transplanting Equipment and Technology, Hangzhou 310018, China.

\section{Authors' Information}

Yaxin Yu, is currently an associate professor and a master's supervisor at Key Laboratory of Transplanting Equipment and Technology, Zhejiang Sci-Tech University, China. Her main research interests include mechanical design and mechanical dynamics.

Jikun Liu, is currently a master candidate at Key Laboratory of Transplanting Equipment and Technology of Zhejiang Sci-Tech University, China.

Bingliang Ye, is currently a professor and a PhD candidate supervisor at Key Laboratory of Transplanting Equipment and Technology, Zhejiang Sci-Tech University, China. His main research interests include agricultural machinery innovation design, mechanism kinematics and dynamics and mechanical optimization design.

Gaohong Yu, is currently a professor and a PhD candidate supervisor at Key Laboratory of Transplanting Equipment and Technology, Zhejiang Sci-Tech University, China. His main research interests include agricultural machinery innovation design, mechanism kinematics and dynamics and mechanical optimization design.

Xuejun Jin, received his master degree from Zhejiang Sci-Tech University, China, in 2017.

Liang Sun, is currently an associate professor and a master's Supervisor at Key Laboratory of Transplanting Equipment and Technology, Zhejiang Sci-Tech University, China. His main research interests include mechanism synthesis, mechanical simulation technology and agricultural machinery.

Junhua Tong, is currently a lecturer at Key Laboratory of Transplanting Equipment and Technology, Zhejiang Sci-Tech University, China. His main research interests include mechanism synthesis, mechanical simulation technology and agricultural machinery.

\section{Funding}

Supported by National Key Research and Development Program of China (Project No. 2017YFD0700800), Zhejiang Provincial Natural Science Foundation of China (Grant No. LZ16E050003), Natural Science Foundation of China 
(Grant No. 51505429), and Science Foundation of Zhejiang Sci-Tech University (Grant No. 15022011-Y).

\section{Competing Interests}

The authors declare that they have no competing interests.

Received: 6 June 2018 Accepted: 19 April 2019

Published online: 22 May 2019

\section{References}

[1] Z J Lv, Y Y Shan, J Wang, et al. Research progress of vegetable transplanting machine and prospects of seedling picking machinery of transplanter. Journal of Chinese Agricultural Mechanization, 2017, 38(11): 30-34. (in Chinese).

[2] HY Zhou, B N Yang, H Yan, et al. Status quo and development prospects of dry land transplanting machine industry. Agricultural Engineering, 2015, 5(1): 12-13. (in Chinese).

[3] J Wang, D D Du, J B Hu, et al. Vegetable mechanized harvesting technology and its development. Transactions of the Chinese Society for Agricultural Machinery, 2014, 45(2): 81-87. (in Chinese).

[4] XXYu, Y Zhao, B C Chen, et al. Current situation and prospect of transplanter. Transactions of the Chinese Society for Agricultural Machinery, 2014, 45(8): 44-53. (in Chinese).

[5] Kumar G V Prasanna, Raheman H. Vegetable transplanters for use in developing countries-a review. International Journal Vegetable Science, 2008, 14(3): 232-255.

[6] T Konosuke. Development of fully automatic vegetable transplanter. Japan Agricultural Research Quarterly, 2000, 34(1): 21-28.

[7] W C Choi, D C Kim, I H Ryu, et al. Development of seedling pick-up device for vegetable transplanters. ASAE, 2001, 45(1): 13-19.

[8] L N Shaw. Automatic transplanter for vegetables. Proceedings of Florida State Horticultural Society, 1997, 110: 262-263.

[9] Xiang, M L Wu, Y J Xu. Present status and prospects of seedling transplanting machinery. Journal of Agricultural Mechanization Research, 2015, 37(8): 6-9, 19. (in Chinese).

[10] X B Yuan, G F Zhang, J N Chen, et al. Development on rice plotted-Seedling sequential transplanter. Journal of Zhejiang Sci-Tech University, 2011, 28(5): 749-753. (in Chinese).

[1 1] L M Xu, T Z Zhang, Z Q Shi. Design on the picking seedling machinery in the maize auto transplanter. Journal of China Agricultural University, 2000, 5(4): 58-60. (in Chinese)

[12] S Zhang, S B Tian, L C Qiu, et al. Structure design and simulation on manipulator of transplanting potted tray seedlings. Journal of Shenyang Agricultural University, 2007, 38(3): 437-439. (in Chinese).

[13] D Z Hui. Design and research on the picking seedling machinery of tobacco auto-transplanter. Changsha: Hunan Agricultural University, 2010. (in (hinese).

[14] W Cui, X F Fang, L Zhao, et al. Structural optimization and experimental verification of geared five-bar linkage seedling pick-up device. Transactions of the Chinese Society for Agricultural Machinery, 2013, 44(8): 74-77.

[15] B L Ye, G H Yu, Z W Chen, et al. Kinematics modeling and parameters optimization of seedling pick-up mechanism of planetary gear train and non-circular gear. Transactions of the Chinese Society of Agricultural Engineering, 2011, 27(12): 7-12. (in Chinese).

[16] B L Ye, TTang, G H Yu, et al. Dynamics analysis and experiment seedling pick-up mechanism of planetary gear train with combined non-circular gear transmission. Transactions of the Chinese Society for Agricultural Machinery, 2018, 49(12): 74-82.
[17] B L Ye, H Zhu, G H Yu, et al. Dynamics analysis and tests of rotary transplanting mechanism for rice pot-seedling. Transactions of the Chinese Society for Agricultural Machinery, 2016, 47(5): 53-61. (in Chinese).

[18] B L Ye, G HWu, G H Yu, et al. Optimized design and tests on rice potted seedling transplanting mechanism of planetary gear train with noncircular gears. Transactions of the Chinese Society for Agricultural Machinery, 2016, 47(11): 68-73. (in Chinese).

[19] G H Yu, TF Yu, B L Ye, et al. Design of a rotary plug seedling pick-up mechanism. Journal of Mechanical Engineering, 2015, 51(7): 67-76. (in Chinese).

[20] G H Yu, J P Yu, J H Tong, et al. Design of a conjugate concave-convex non-circular gear mechanism. China Mechanical Engineering, 2016, 27(16): 2155-2159, 2165. (in Chinese)

[21] X Zhao, HY Cui, L Dai, et al. Kinematic analysis and experimental research on the seedling pick-up mechanism of a second-order free noncircular planetary gear system. Applied Engineering in Agriculture, 2017, 33(2): 169-179.

[22] X Zhao, CWang, M X Yang, et al. Reverse design and analysis of automatic seedling pick-up mechanism with non-circular gear planetary train. Transactions of the CSAE, 2015, 31(16): 30-36. (in Chinese).

[23] X Zhao, M Shen, J N Chen. Seedling pick-up mechanism of planetary gear train with two-order general non-circular gears. Transactions of the Chinese Society for Agricultural Machinery, 2014, 45(4): 123-127. (in Chinese).

[24] YW Wang, Z L He, J Wang, et al. Experiment on transplanting performance of automatic vegetable pot seedling transplanter for dry land. Transactions of the Chinese Society of Agricultural Engineering, 2018, 34(3): 19-25. (in Chinese).

[25] M F Zhou, G H Yu, Y Zhao, et al. Parameters optimization and test on pickup mechanism of planetary gear train with ellipse gears for vegetable plug seedling. Transactions of the Chinese Society of Agricultural Engineering, 2014, 30(18): 13-21. (in Chinese).

[26] X J Jin. Optimization design and tests of seedling pick-up mechanism of planetary gear train with combined gear transmission of incomplete eccentric circle gear and non-circular gears. Hangzhou, China: Zhejiang Sci-Tech University, 2017. (in Chinese).

[27] M B Qian, H G Yu, X F Zhang, et al. Design method and fatigue strength analysis of eccentric-noncircular gear transmission mechanism. Journal of Jiangsu University, 2016, 37(1): 44-48, 109.

[28] B L Ye, W M Yi, G H Yu, et al. Buffer device of transplanting mechanism for plug seedlings based on transmission with incomplete non-circular gears. Transactions of the Chinese Society for Agricultural Machinery, 2017, 48(3): 69-75. (in Chinese)

[29] B L Ye, L Li, G H Yu, et al. Design and test on cam mechanism of seedling pick-up arm for vegetable transplanter for pot seedling. Transactions of the Chinese Society of Agricultural Engineering, 2014, 30(8): 21-29. (in Chinese).

[30] Y Gao. Optimization design and tests of rice pot-seedling transplanting mechanism of planetary gear train with incomplete eccentric circle gear. Hangzhou: Zhejiang Sci-Tech University, 2016. (in Chinese).

[31] B L Ye, W M Yi, G H Yu, et al. Optimization design and test of a rice plug seedling transplanting mechanism of planetary gear train with incomplete eccentric circular gear and non-circular gears. International Journal of Agricultural and Biological Engineering, 2018, 11(1): 32-39.

[32] B L Ye, XJ Jin, G H Yu, et al. Parameter modification guiding optimization design and tests of a rotary transplanting mechanism for rice plug seedlings. Applied Engineering in Agriculture, 2015, 31 (6): 863-873. 